\title{
Blended Learning Platforms
}

\section{Maria Cristina ENACHE ${ }^{\star}$}

\begin{tabular}{l}
\hline \multicolumn{1}{c}{ A R T I C L E I N F O } \\
\hline Article history: \\
Accepted March 2021 \\
Available online May 2021 \\
\hline JEL Classification \\
K22, M21 \\
Keywords: \\
e-learning, e-learning platforms, \\
Model
\end{tabular}

\begin{abstract}
A B S T R A C T
Blended learning combines the advantages of in-person learning with online technology tools. Pre and during the COVID-19 pandemic, teachers used multiple methods to understand its value to educational outcomes and how space can play a role to ensure an enhanced experience. A viable model for the future of education is blended learning, and face-to-face and online components can be combined in any proportion, whether it is assessment or classroom participation. Each student can find a unique blend of the two that best suits their own personal learning style and adapts to the family situation and the level of access to technology.
\end{abstract}

(C) 2021 EAI. All rights reserved.

\section{Introduction}

It is impossible to find a single definition of blended learning: there are as many ways to combine time face-to-face with online class and lessons as there are students and teachers. Blended learning is useful in this pandemic context to reduce physical frequency in favor of video conferencing, to create smaller groups that allow for adequate social distancing. Just like giving up blended learning for frontal lessons as the predominant way of teaching, it will be a mistake.

If there is one thing that has shown the sudden and forced transition to distance learning, in fact, it is that not all households are equally prepared to switch to distance learning: with a personal device and a stable Internet connection as necessary in order not to be left behind, the digital divide between those who can meet the new basic needs of the contemporary world and those who cannot is wider than ever, and physical participation is still the only option for minors living in two-income households, which considers the school not only as a place of learning, but also as a safe space that ensures the supervision of adults while both parents work. Given this situation, personalized learning that takes these factors into account is the ideal compromise for a post-pandemic society.

Since the onset of the pandemic, the question has arisen of how learning is affected in this new context, how it influences online learning and what the impact is for teachers and students. They heard that the students missed the campus experience. Physical space is more than learning. As one student put it, "Campus experience is several things: your job, friends, campus events, being with others, trying our stuff, and studying it. Another said: "(I) would prefer a hybrid format ... online interactions cannot replace real physical interactions."

Meanwhile, students can collaborate seamlessly with classmates, submit digital assignments, and access classroom materials outside of regular school hours. Preliminary research suggests that digital platforms may improve student test scores.

\section{E-learning platform}

With schools all over the world redesigning because of COVID-19, blended learning is becoming a new normal. Blended learning has been around for a while and is the combination of traditional face-to-face instruction with aspects of online instruction all while students are in the classroom with the teacher. Blended learning strives to provide students the best of both face-to-face and online learning experiences. Blended classrooms include face-to-face instruction techniques such as direct instruction or lecture, group discussions, and small-group work while also using technology to provide in-class online learning that students can do at home provided they have access to necessary technology.

Online instruction is often facilitated by an e-learning platform. An e-learning platform can be used both in a face-to-face study context and on a distance learning model. An e-learning platform includes specific procedures and tools to facilitate individual study at your own pace, with diversified means of study, easily accessible through: 
- implementation of procedures for registration and personalization of the interface both for students and for instructors and administrator.

- ensuring synchronous and asynchronous communication between students and instructors.

- specific tools for recording, monitoring, and archiving in safe conditions all information about and for students.

The e-learning platform is a technological solution capable of providing individual and / or group online assistance to students, which has specialized programs, both for collecting statistical data about students and for using them to improve the services offered, to provide users informed from the system, information on calling and using the available educational services, to provide facilities for: online help, map of the learning environment, structure of the web page on which the course or tutorial support is implemented, how to use the icons, etc.

The e-learning platform should ensure that students have access to various study and communication resources, synchronous and asynchronous group discussions, the virtual library and provide specific means of online assessment and self-assessment of the knowledge acquired by students. The platform must have facilities to periodically collect the feedback of the students on the educational services offered to them and, at the same time, to provide the students with detailed information, in electronic format, regarding the activities carried out. Considering the ones written above listed above, the use of an e-learning platform by students involves the use of specialized tools for carrying out specific online educational activities: accessing information and browsing, online assessment, communication.

The choice of the pedagogical model must be a rigorous process, determined by a preliminary analysis. The choice should be based on three major factors: training needs; information needs; the required pedagogical performances.

The pedagogical model of an e-learning platform is built based on a learning matrix centered on two axes: task and cooperation. Based on this model there are four types of learning differentiated by the level of support provided and the level of learning control.

Sharing Experiences - relating, participating, and sharing are necessary conditions. Thus, the appropriate tools for collaborative communities used on the e-learning platform are forum, blog, and wiki.

Collaboration - Collaboration aims at a higher level of involvement in solving tasks, but also the interaction necessary to achieve them, both between instructors and students and between students. Thus, the appropriate tools for collaboration on the e-learning platform are forum and chat.

Support resources - Support resources are the necessary tools for organizing and managing content, as the e-learning platform provides mechanisms for adding, modifying, and deleting educational content, functions characteristic of a content management system.

Self-learning - Transfers content through self-learning and knowledge verification through simulation and examination. This way of self-training proves to be very useful for the acquisition of theoretical knowledge for the disciplines in which the student is a student.

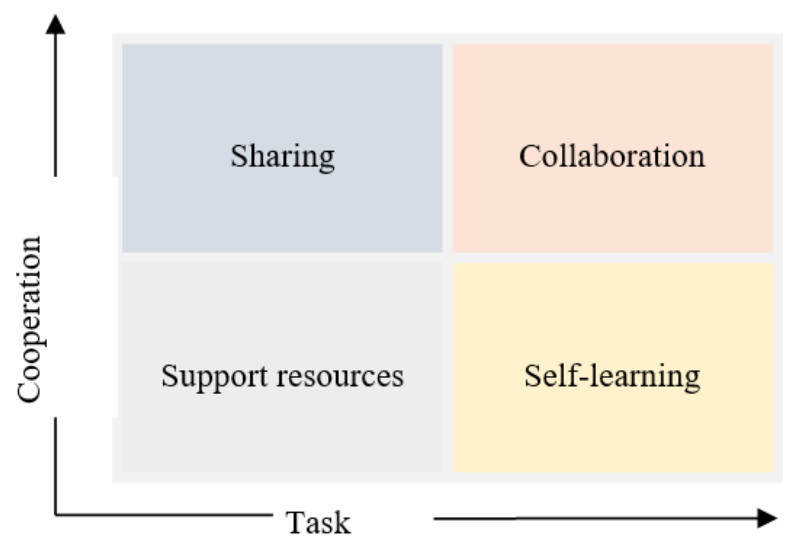

Figure 1. Pedagogical principles of a blended learning platform

In its simplest form, an e-learning platform brings together in one place a wide variety of useful information resources, grouped into categories, in order to help users, avoid the clutter of information they may face, but can emulate an information system as a whole, which can include in addition to the necessary information resources, many other solutions and applications used in the phases of data collection, processing and storage to decision support and support for working groups. 


\section{Services in e-learning platform}

The services of an e-learning platform should include:

- functional procedures, implemented both for the registration of instructors and students

- communication facilities between the educational actors involved

- technological solutions capable of providing online and / or group online assistance to students

- mechanisms for collecting statistical data about students, to improve the services provided

- providing information on calling and using the available educational services, to all users approved by the system

- providing online help facilities or a map of the learning environment, or how to use the icons, etc.

- ensuring the accessibility of different study and communication resources related to news, correspondence, chat or forum discussions, or the virtual library

- providing specific means of online assessment and self-assessment of the knowledge acquired by students

- administrative procedures through which each user defines the context of his own activity in the training process

- popular procedures of the platform with educational content, teaching materials, tests, homework, video tutorials

- information procedures regarding the educational process through announcements, warnings about events

- $\quad$ procedures to support the educational process

- search procedures

- procedures for controlling the quality of the educational act through surveys, questionnaires, and statistics

- facilities for periodically collecting the students' feedback on the educational services offered to them.

Specific learning resources - An e-learning platform should include specific procedures and tools that facilitate individual study at their own pace, with diversified means of study, easily accessible. For this we started from the idea that:

- the teaching staff involved will assume responsibility for the development and implementation of the courses on the platform

- procedures will be implemented for conducting new courses

- procedures will be implemented regarding the updating of the courses and their educational support

- specific tools will be provided for the development and implementation of courses in multimedia format, accessible through the Internet.

Access to the services offered - The platform we refer to has been implemented in a communication infrastructure that allows constant and simultaneous access of an average number of users and to properly handle various electronic aspects of study resources. The following issues need to be considered:

- to allow the simultaneous access of an average number of users

- use the existing network inside the institution to allow access to the platform of all registered users, regardless of their location.

The context and premises of use will emerge from the following questions:

- Why a platform? - The need for a platform arose when the volume of information resources became very high.

- How can the strategic objectives of the institution be achieved by using this technology? - an elearning platform is intended to be a communication tool and a way to build a certain computerassisted training community, materialized on common areas of interest. Providing online education as well as obtaining the information needed to make decisions much faster is a strategic advantage of implementing this platform.

- How quickly will the technology be assimilated? - The use of web technologies, in finding and manipulating information, has made assimilation faster, especially since most of the beneficiaries have an age of curiosity and knowledge exploiting to the maximum all the facilities that will be made available to them. The more rigid aspect of the implementation of an e-learning platform was and still is constituted by the group of instructors reluctant to modern technical means.

- What services can be provided or needed? - Existence of the need to provide services to ensure continuous training.

Security and privacy - Much of the users' personal information may be available from almost any area of the platform, which requires the implementation of authentication, authorization, and encryption mechanisms to prevent unauthorized access. Thus, access is based on a username and password, initially 
assigned by the administrator. The username can only be changed upon request, but the password can be changed at any time.

An important aspect is the choice of the data management mode, in other words the platform administration model. Platform development policies classify administration into two broad categories:

- Centralized, for which resources, policies, strategies, and decisions are established at a central level which ensures the maintenance of unity and uniformity in the organization of the platform but proves rigid in front of the structures subordinated to the institution.

- Decentralized or distributed - as it is also known - the federal model, with two categories of decision elements:

○ a central authority that has already established the platform's orientation towards lifelong learning

- entities such as departments and instructors who will determine how to improve the educational instruction process according to their own criteria.

The implementation of the governance mode considers:

- granting the privileges through which it is possible to delegate the responsibilities of management and development of the platform

- delimitation of user groups, which is necessary to achieve a better identification and structuring of resources

- $\quad$ autonomy to be able to establish and implement its own policies and strategies

- flexibility to ensure the development within the limits of the central policies of certain courses, or instructional materials, without affecting the other courses, disciplines or other entities, which ensured a diversity in the overall development of the platform

- the possibility of achieving correlations between learning units, which should ensure the implementation of common policies and strategies

- $\quad$ ensures the delimitation of the decision power.

The use of an e-learning platform can be done in several ways:

- $\quad$ as a simple visitor who has access to all general information

- $\quad$ as a user with a student account who has access to all learning units specific to his form of study, which he can download so that he can study them offline. The courses should contain theoretical support, video files intended to increase the quality of the learning process and demonstration tests

- $\quad$ as a user with an instructor account who has access to all related learning units for the current year. He may be allowed access to the situation of students following the course they hold

- as a full-fledged administrator.

A platform should be designed considering the particularities of e-learning 2.0 systems from a conceptual point of view and have specific procedures to ensure the implementation, virtually, of teaching activities, but also the interaction of the following user groups:

- teachers who will support the educational instructional process

- students as beneficiaries of the activities carried out by the other user groups

- the administrator who ensures the optimal framework for the operation of the platform.

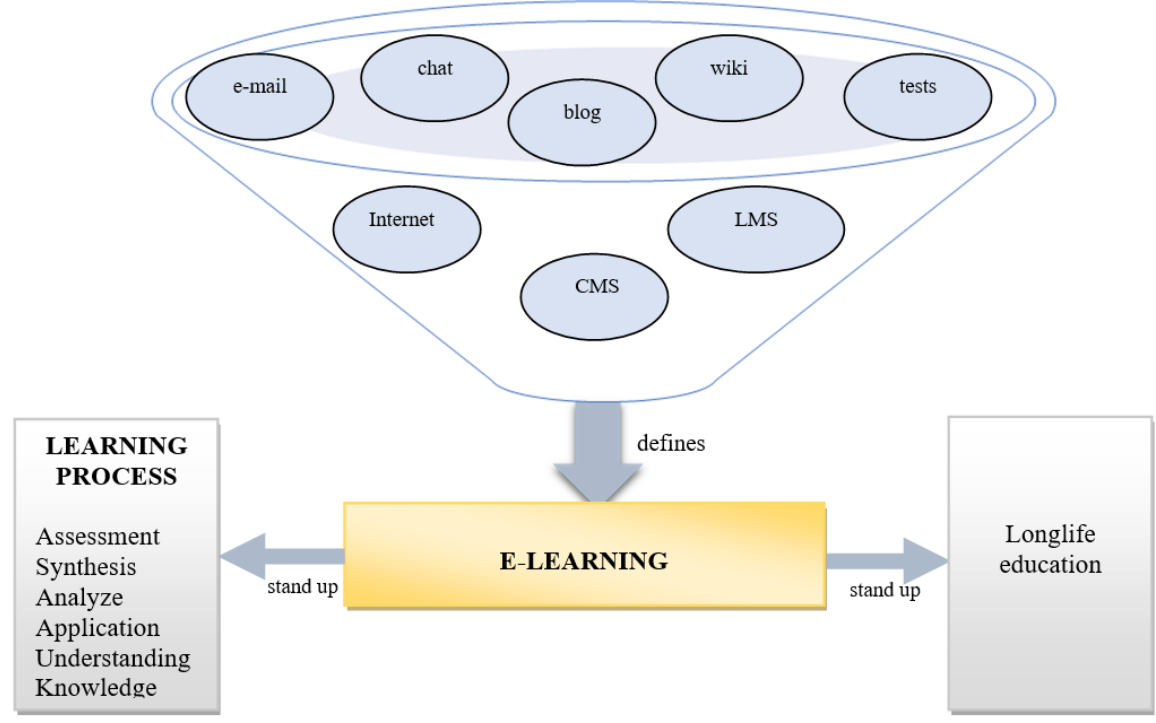

Figure 2. E-learning platform principles 
From an architectural point of view, an e-learning platform can be structured in three subsystems:

- the subsystem of learning activities - here are included the modules for visualizing the learning units, the simulation and testing modules

- the auxiliary learning subsystem - this includes the modules for coordination and collaboration provided by the platform

- the subsystem for instructors - here are included the modules for creating educational materials, uploading them, managing questions and questionnaires for simulation and / or examination.

The e-learning platform should provide support for the organization of an education system exclusively through the Internet, through a very complex structure and functionality, which includes:

- a public section, generally accessible, having an informative character

- an administrative section

- private sections for students, instructors, and administrative staff.

\section{Conclusions}

Our conclusions regarding the use of an e-learning platform for blended learning are the following:

- an e-learning platform proves to be a beneficial communication environment between the two important parties involved in the educational process: the student and the teacher. The intuitive and easily accessible interface facilitates the bidirectional transfer of information

- a better management of the presence and of the results obtained by each student can be ensured

- an interactive and intuitive testing part can be provided

- flexibility and easy administration.

Another conclusion of our research is that e-learning systems and cutting-edge technologies have not yet produced revolutionary changes in the field of education. They have only been used to improve and increase the efficiency of training practices in various educational institutions. A fundamental change has not yet taken place, although the approach to these technologies for distance learning is clear. We believe that this is an example of the direction in which our future research should go in relation to information technology and education. All these major changes in the training processes and obtaining information about the students' preferences, to support their continuing education approaches, only contribute to the formation of the individual, adding value to the classical education process.

\section{References}

1. https://www.edweek.org/teaching-learning/opinion-blended-learning-in-the-age-of-covid-19/2020/08

https://us.sagepub.com/en-us/nam/teaching-with-e-learning-in-the-lifelong-learning-sector/book238394

https://www.edweek.org/education/opinion-q-a-collections-implementing-the-common-core/2019/07

https://acerforeducation.acer.com/blended-learning/covid-19-will-blended-learning-become-the-future-of-education/

European Commission, Education and Training, http://europa eu.int/comm/education/eLearning

EDEN: European Distance and E-Learning Network: http://www.eden-online.org/eden.php 